\title{
Systematics and historical biogeography of (1) comasate the old world butterfly subtribe Mycalesina (Lepidoptera: Nymphalidae: Satyrinae)
}

Kwaku Aduse-Poku*, Oskar Brattström¹, Ullasa Kodandaramaiah ${ }^{1,2}$, David C. Lees ${ }^{1}$, Paul M. Brakefield ${ }^{1}$ and Niklas Wahlberg ${ }^{3}$

\begin{abstract}
Background: Butterflies of the subtribe Mycalesina have radiated successfully in almost all habitat types in Africa, Madagascar, the Indian subcontinent, Indo-China and Australasia. Studies aimed at understanding the reasons behind the evolutionary success of this spectacular Old World butterfly radiation have been hampered by the lack of a stable phylogeny for the group. Here, we have reconstructed a robust phylogenetic framework for the subtribe using 10 genes from 195 exemplar taxa.

Results: We recovered seven well supported clades within the subtribe corresponding to the five traditional genera (Lohora, Heteropsis, Hallelesis, Bicyclus, Mycalesis), one as recently revised (Mydosama) and one newly revised genus (Culapa). The phylogenetic relationships of these mycalesine genera have been robustly established for the first time. Within the proposed phylogenetic framework, we estimated the crown age of the subtribe to be 40 Million years ago (Mya) and inferred its ultimate origin to be in Asia. Our results reveal both vicariance and dispersal as factors responsible for the current widespread distribution of the group in the Old World tropics. We inferred that the African continent has been colonized at least twice by Asian mycalesines within the last 26 and 23 Mya. In one possible scenario, an Asian ancestor gave rise to Heteropsis on continental Africa, which later dispersed into Madagascar and most likely back colonised Asia. The second colonization of Africa by Asian ancestors resulted in Hallelesis and Bicyclus on continental Africa, the descendants of which did not colonise other regions but rather diversified only in continental Africa. The genera Lohora and Mydosama are derivatives of ancestors from continental Asia.
\end{abstract}

Conclusion: Our proposed time-calibrated phylogeny now provides a solid framework within which we can implement mechanistic studies aimed at unravelling the ecological and evolutionary processes that culminated in the spectacular radiation of mycalesines in the Old World tropics.

\section{Background}

As a subtribe, Mycalesina Reuter, 1896 is considered to be one of the most spectacular evolutionary radiations of butterflies in the world [1]. Butterflies of this subtribe, referred to as mycalesines, are arguably the most cosmopolitan and abundant group of butterflies restricted to the Old World tropics. Consequently, they are used extensively in ecological (e.g. [2-5]) and evolutionary (e.g. [6-9]) research. There are at least 300 currently

\footnotetext{
*Correspondence: ka374@cam.ac.uk

'Department of Zoology, Radiating Butterflies Group, University of

Cambridge, Downing Street, Cambridge CB2 3EJ, UK

Full list of author information is available at the end of the article
}

recognised species belonging to Mycalesina occurring in almost all terrestrial habitat types across all the major paleotropical regions (Africa, Madagascar, Asia and Australasia). However, the factors leading to the evolutionary success of this species-rich paleotropical butterfly group in the World Old tropics are not yet fully understood. Knowledge on where and when important divergences have occurred within the group is vital to our understanding of this spectacular Old World radiation. This primarily requires a robust phylogenetic framework for the entire subtribe, which is currently lacking.

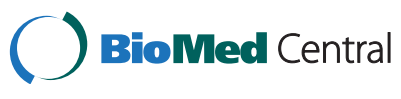

(c) 2015 Aduse-Poku et al. Open Access This article is distributed under the terms of the Creative Commons Attribution 4.0 International License (http://creativecommons.org/licenses/by/4.0/), which permits unrestricted use, distribution, and reproduction in any medium, provided you give appropriate credit to the original author(s) and the source, provide a link to the Creative Commons license, and indicate if changes were made. The Creative Commons Public Domain Dedication waiver (http://creativecommons.org/publicdomain/zero/1.0/) applies to the data made available in this article, unless otherwise stated. 
The alpha-taxonomy of this butterfly group is currently fairly well-known and relatively stable (perhaps less so in the group in Asia), compared to at least other species-rich paleotropical groups such as Ypthimina, in the region. However, the higher level taxonomy of Mycalesina is not yet adequately resolved. The current generic circumscriptions of mycalesines have been based on a few morphological characters such as the presence or absence of hairy eyes (interommatidial setae), forewing venation and androconial structures [10-15], which have been considered by some authors (e.g. $[16,17])$ as parochial and an inadequate character sets for resolving their systematics. The higher level taxonomic uncertainty is partly attributable to earlier authors dividing the subtribe into African, Malagasy and Asian mycalesines. Although reasons for this geographic division have not been explicit, except perhaps to assume that large water gaps could delimit the hierarchy of nature, subsequent authors have followed the trend of studying the mycalesine fauna at regional levels.

The bulk of the continental African species were separated from all other mycalesines by Condamin [15]. Apart from two species he considered particularly distinct that he placed in the genus Hallelesis Condamin, 1961, the rest were placed in Bicyclus Kirby, 1871. Although Condamin first introduced Hallelesis in 1960, he omitted to assign a type species and so rectified this mistake a year later. Condamin's revisionary work spanned more than a decade and his comprehensive revision of Bicyclus was summarized in an extensive monograph [10]. The genera Hallelesis and Bicyclus (with two and about 90 currently recognised species, respectively) are distributed almost exclusively on sub-Saharan continental Africa with a single species (B. anynana) extending its distributional range to the Comoros and Socotra Islands, both in the Indian Ocean [16, 17]. The Socotran subspecies (B. anynana socotrana) was originally placed in the Asian genus Calysisme Moore, 1880 despite limited morphological similarities, demonstrating further the entrenched and parochial approach employed by earlier authors in delineating mycalesine groups geographically.

Nearly two and half decades after the publication of Condamin's work, Lees [13] undertook a similar revisionary treatment of the mycalesines on Madagascar, and arranged them under five pre-existing generic names: Admiratio Hemming, 1964, Masoura Hemming, 1964, Henotesia Butler 1879, Heteropsis Westwood, [1850] and Houlbertia Oberthür, 1916. However, a subsequent phylogenetic study [18] based on two mitochondrial markers found that most of the Malagasy mycalesine genera were not monophyletic, prompting taxonomic changes of the group on the island. Lees and colleagues [19] followed up and radically revised the taxonomy of mycalesines on the island; synonymising the genus Houlbertia and downgrading four preexisting genera to the status of subgenera under a single genus, Heteropsis Westwood, [1850]. At the moment, there are about 75 Heteropsis taxa recognised in the Malagasy region, of which about a third are still undescribed [13]. Heteropsis occurs on continental Africa as well, with all 13 currently recognised species belonging to the (sub) genus Henotesia [20, 21].

The Oriental and Australasian mycalesines have gone through several regional taxonomic revisions. The first major treatment of the group as a whole was made by Moore [12] who divided all Asian mycalesines into 23 genera based primarily on androconial configurations and wing venation. As many as 10 of these new genera were described as monotypic, and this rather extreme splitting was later criticised by other authors (e.g. [22, 23]). Fruhstorfer returned all species to Mycalesis, using only two subgenera, but retained Orsotriaena Wallengren, 1958 (that had previously been given equal status as all the other genera created by Moore), separate from all other species that were now merged again as subgenus Mycalesis. Unfortunately, Fruhstorfer's work seems to have been somewhat neglected since Moore's numerous genera remained in use in mainly English texts until they were again demoted by Evans [24] who, just like Fruhstorfer, considered Orsotriaena separate, but gave both of Fruhstorfer's subgenera full generic status. Orsotriaena has subsequently been shown in recent molecular studies not be closely related to Mycalesina [25, 26].

Following the taxonomic revision of the group by Evans [24], Moore's genera [12] were treated as subgenera in some later works. The most important later taxonomic modifications of the Asian Mycalesina were the inclusion of the odd mimetic species $M$. drusillodes (originally described as Hamadryopsis drusillodes Oberthür, 1894 with the female in the same work as Drusillopsis dohertyi) into Mycalesis [27], and the separation of 19 mycalesine species confined to the Sulawesi and Sula islands [14, 28, 29] . These last endemic taxa were treated separately as the genera Nirvanopsis, Vane-Wright, 2003 and Lohora Moore, 1880, with two and 17 recognised species, respectively. However, a recent molecular study found the two Nirvanopsis taxa nested within Lohora and thus the former was subsumed within the latter to reflect phylogeny [30]. Kodandaramaiah and colleagues [30] also split the genus Mycalesis into two genera, with the clade containing the type species of the genus (Papilio francisca) classified as Mycalesis sensu stricto, while the other well supported clade was placed under the genus Mydosama Moore, 1880 (with Dasyomma fuscum Felder \& Felder, 1860 as the type species). 
The rather turbulent taxonomic history of mycalesines at generic and subgeneric levels has allowed very little progress in our understanding of the interrelationships between the main groups on the different continents. To date, there is no robust phylogenetic framework establishing with appreciable confidence the interrelationships among the six current genera and the many species groups of mycalesines distributed in the different regions of the Old World tropics. Such a framework is crucial to facilitate further studies from the species level to entire radiations, and also to form a stable basis for the higherlevel taxonomy of the subtribe. In this study, we have used 10 genes and about 200 exemplar taxa to infer the phylogenetic relationships of species across the entire subtribe Mycalesina. Within the proposed phylogenetic framework, we have estimated times and places of major divergences, and related these with external factors that may have contributed to the success of this subtribe of palaeotropical butterflies.

\section{Results \\ Systematics}

The final molecular data matrix comprised 195 taxa representing 185 mycalesine species and 10 related taxa as outgroups. More than $75 \%$ of the sampled exemplar taxa had at least half of the total gene coverage, with the average coverage per taxon being $c a .70 \%$ (Additional file 1: Table S1). The resultant alignment consisted of 7735 base pairs of which $46 \%$ and $35 \%$ were variable and parsimony informative sites, respectively. The best partitioning schemes and the optimal evolutionary models for each of the partitioned dataset for the RaxML analyse are listed in Additional file 2: Table S2. The Effective Sample Sizes (ESS) for all the parameters of the different independent Markov Chain Monte Carlo (MCMC) runs in the Bayesian analysis were higher than 200. The Combined ESS for the parameters of the three independent BEAST runs are presented in Additional file 3: Table S3.

Our results revealed seven well supported higher clades within Mycalesina (Fig. 1, Additional file 4: Figure S1). Both the Maximum Likelihood (ML) and Bayesian Inference (BI) methods recovered the subtribe Mycalesina as monophyletic with high posterior probabilities (PP) and strong bootstrap supports (BS). Likewise the monophyly of four of the six currently circumscribed genera (Bicyclus, Hallelesis, Mycalesis and Lohora) within Mycalesina were well supported in all the analyses. The Asian mycalesine taxa were recovered as four distinct clades in all the phylogenetic reconstruction methods. One of the Asian clades which for convenience is referred to here as the "Asian Heteropsis clade", includes Mycalesis oculus, M. adolphei, M. sangaica, M. malsara, M. inopia, M. nicotia/misenus, $M$. mamerta and M. janardana. This clade was nested within the Afro-Malagasy Heteropsis clade with high support in both ML $(\mathrm{BS}=95)$ and $\mathrm{BI}(\mathrm{PP}=1)$ methods. The two major Asian clades (Mycalesis and Mydosama) grouped together but with moderate to high support $(\mathrm{PP}=0.99$, $\mathrm{BS}=56$ ). The topologies were congruent between the different phylogenetic analyses. Mycalesis included as its members the type species of the currently circumscribed genus Mycalesis, M. francisca, and taxa such as M. sudra, M. visala, M. gotama, M. patnia, M. mineus, $M$. oroatis (see Fig. 1 for full list). Most species of Mycalesis were found to be distributed largely on mainland Asia, with the exception being $M$. perseus, which extends its distributional range to the Sundaland, Moluccas and Australasian regions. Mydosama, however, comprised taxa such as $M$. fuscum, M. sara, M. discobolus, M. itys, M. mucia and 30 others, which are predominantly distributed on the islands of South-east Asia and Australasia. The last distinct clade comprised of two taxa, M. mnasicles and M. amoena (Fig. 1, Additional file 4: Figure S1).

The evolutionary relationships between the seven identified higher clades within Mycalesina were largely congruent among the different phylogenetic analyses with moderate to high support (Fig. 1). Lohora (together with Nirvanopsis) was recovered as the sister clade to all other mycalesines. The two African genera, Bicyclus and Hallelesis, clustered with high to moderate support values $(\mathrm{PP}=0.99, \mathrm{BS}=61 \%)$ as sister clades in all analyses. The Bicyclus + Hallelesis clade grouped with the two Asian mycalesine clades as sister groups, but this relationship was weakly supported in the ML tree. The Heteropsis lineages of the different geographic regions were recovered as well supported monophyletic groups, with the Africa and Asian clades being more closely related than either is to their congenerics on Madagascar. Together, the three continental clades constituted a well-supported Heteropsis clade ( $\mathrm{PP}=1, \mathrm{BS}=100 \%)$ which was sister to other mycalesines, except Lohora.

\section{Diversification times}

Our divergence time analyses indicate that the common ancestors of the subtribes Mycalesina and Lethina diverged from each other in the Eocene, about 39.8 Mya, with $95 \%$ highest posterior densities (HPD) of 34.2-45.0 Mya (Fig. 2). However, the first major divergence within Mycalesina was not observed until 12 Mya after the Mycalesina-Lethina split. This basal cladogenesis in the mid Oligocene (28 Mya; HPD, 23.8-32.3 Mya) gave rise to the Sulawesi endemic genus, Lohora. Subsequent to the split of Lohora, the follow-up basal divergences within Mycalesina have been rapid and in tandem, such that by early the Miocene (around 20 Mya), all the currently circumscribed genera had been established. The divergence between the two endemic African genera 


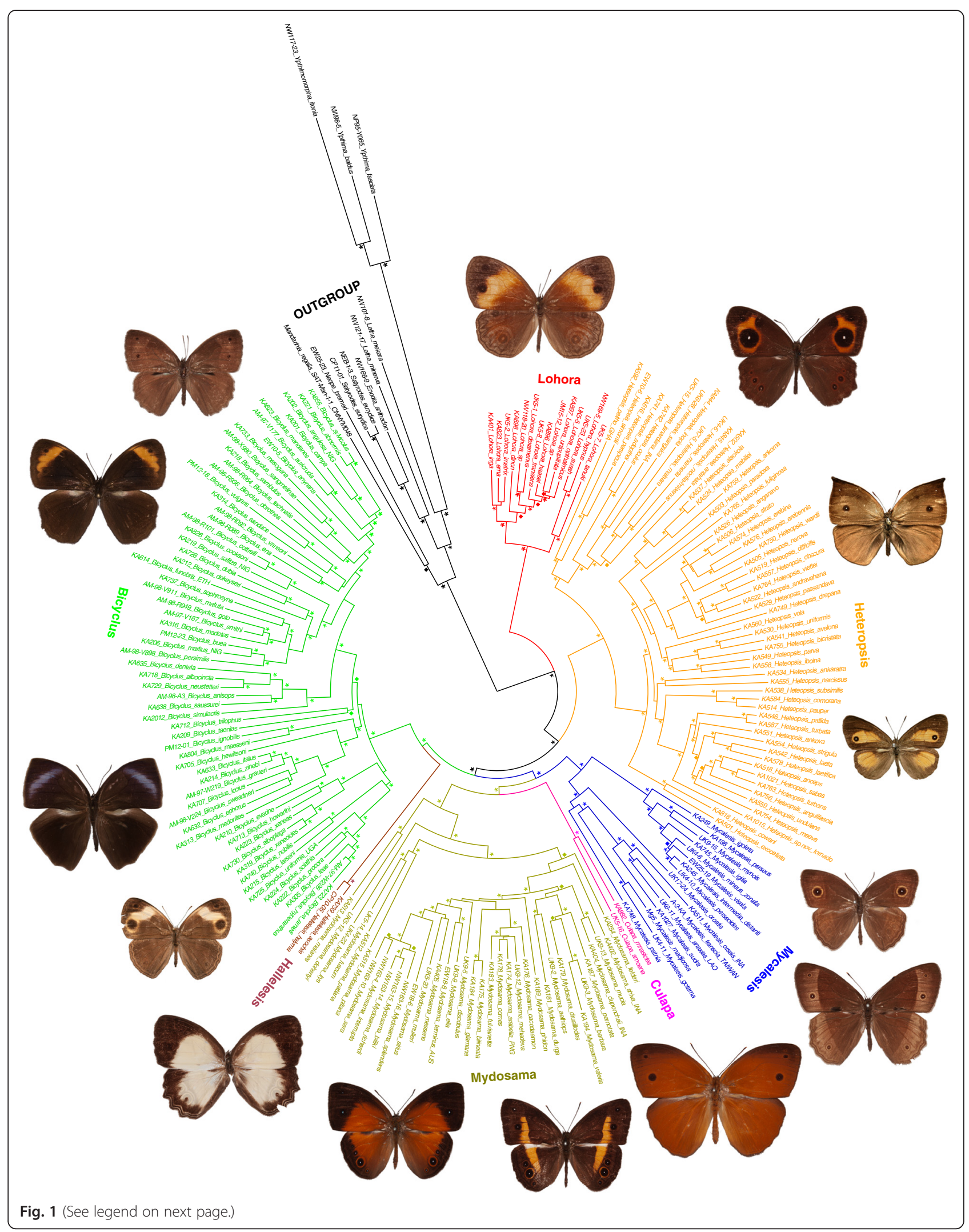


(See figure on previous page.)

Fig. 1 Phylogenetic relationships of the different genera within the subtribe Mycalesina. A (MrBayes) Bayesian phylogeny is shown using the combined 10 genes dataset. An asterisk denotes nodes with posterior probability (PP) more than 0.95. Filled circles are support values (PP) of 0.90-0.94. The colour-coded branches represent the main distinct clades or genera within the subtribe, Mycalesina Reuter, 1896. In a clockwise order starting from the Lohora clade, the exemplar images are Lohora dinon, Heteropsis oculus, H. drepana, H. narcissus, Mycalesis igoleta, Mycalesis sudra, Culapa amoena, Mydosama barbara, Mydosama messene, Hallelesis asochis, Bicyclus larseni, B. graueri, B. matuta and B. vansoni

Bicyclus and Hallelesis was observed to have occurred around the Oligocene and Miocene boundary, roughly at the same time as the split between the two large Asian clades, Mycalesis and Mydosama, is suggested to have occurred. Earlier, Heteropsis (including the lineages in Africa, Madagascar and Asia) had diverged from the other mycalesines in the Oligocene, around 26 Mya (HPD, 23.4-29.8 Mya). However, the two important divergences within the genus giving rise to the extant lineages on the different continents we estimate to have occurred in the mid Miocene. The Malagasy clade was the first to diverge at around 21 Mya (HPD, 17.2-23.3 Mya). The continental African and the Asian Heteropsis clades split about 2.3 Mya later. The onsets of diversifications within most of the genera or higher clades appear to have occurred in the mid Miocene between 20-10 Mya, with the exception of Lohora and Hallelesis. Lohora as a genus only started diversifying around $11 \mathrm{Mya}$, despite being the first mycalesine lineage to diverge around 28 Mya. The only two extant species of Hallelesis (H. halyma and
$H$. asochis) are estimated to have diverged only recently, around 1.6 Mya (HPD, 0.9-2.5 Mya).

\section{Historical biogeography of the subtribe Mycalesina}

Our ancestral area reconstruction analyses suggest that the common ancestors of the subtribes Mycalesina and Lethina were most likely distributed in present-day Asia, making Asia the ultimate origin of the subtribe Mycalesina. Both reconstruction methods identified multiple events of vicariance and dispersal in the historical biogeography of mycalesines. We infer from our results the following scenario. Africa has been colonized at least twice by Asian ancestors. The first observed dispersal event from Asia to Africa resulted in the Heteropsis clades on mainland Africa and Madagascar. The second colonisation of Africa by Asian ancestors gave rise to the two currently circumscribed endemic African genera, Hallelesis and Bicyclus. The split between Hallelesis and Bicyclus most likely occurred in Africa. The mycalesine fauna of the Wallacean and Australasian regions (Lohora

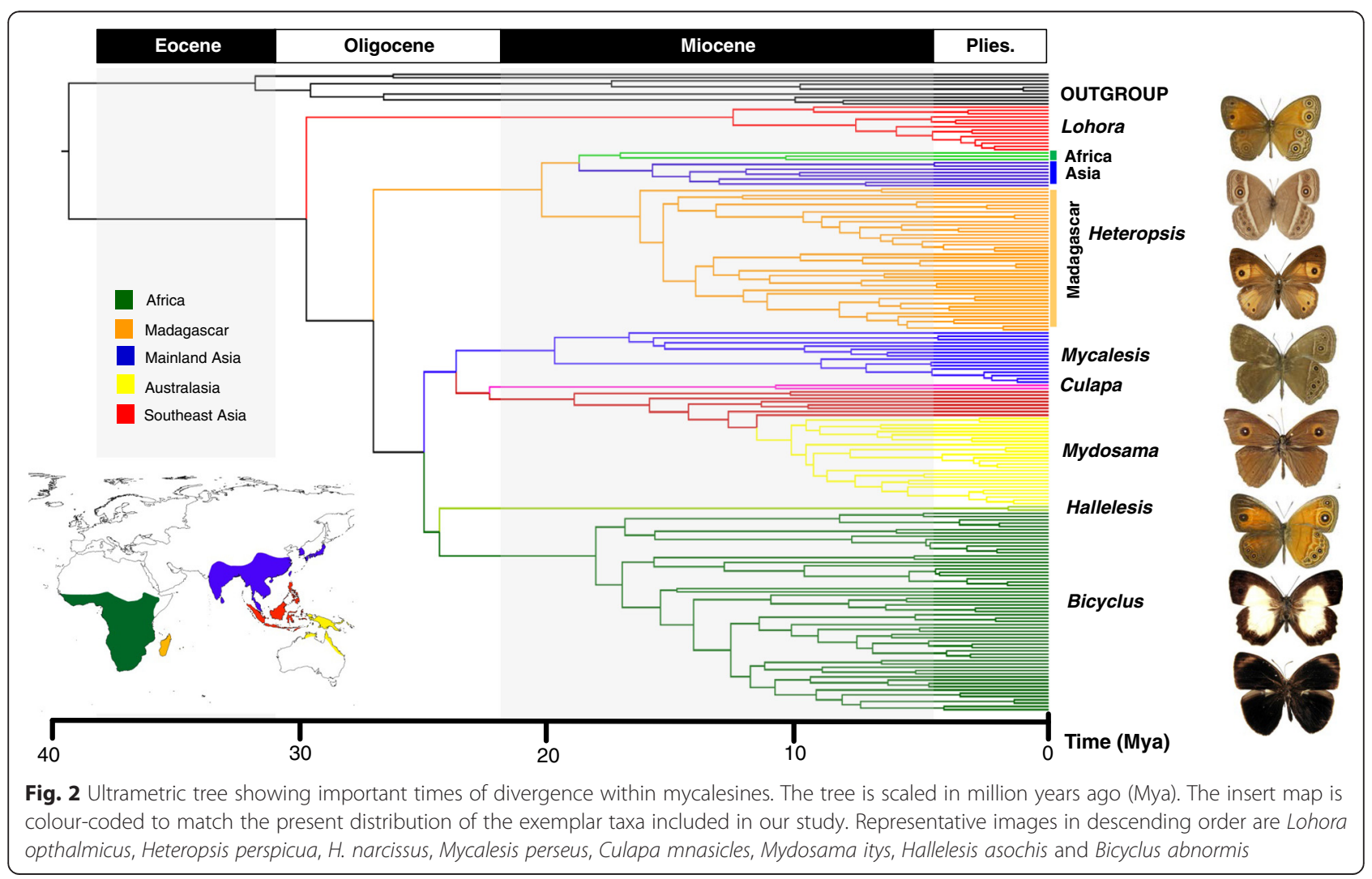


and Mydosama) were derived from ancestors from mainland Asia (Fig. 3).

\section{Discussion}

\section{Systematic implications}

This study represents the most comprehensive molecular investigation of the phylogeny of the subtribe Mycalesina. Before the present study, only one molecular study [30] has made a coherent attempt to classify the entire subtribe Mycalesina. The two other molecular studies of mycalesines $[18,31]$ focused on the group at regional levels. Kodandaramaiah and colleagues [30] used 125 exemplar taxa (of 90 species) and three genes totalling 3139 base pairs (bp) in length in their phylogenetic reconstructions. In this study we have used 195 taxa and 10 gene regions ( $7735 \mathrm{bp})$. The increase in both the number of taxa and genes in the present study appears to have helped to resolve most of the previously unresolved relationships within Mycalesina. Against the backdrop of the taxonomic confusion surrounding the group, especially its members in Asia and Madagascar, we hope that this study will put to rest the frequent taxonomic fluxes within the group. We have established, for the first time with good confidence levels, the evolutionary relationships between the different mycalesine groups of the different palaeotropical regions.

Our phylogenetic hypothesis largely corroborates earlier findings by Kodandaramaiah et al. [30]. For instance, both studies confirmed the monophyly of the subtribe Mycalesina and three higher clades or genera; Bicyclus, Hallelesis and Lohora, with relatively higher nodal supports in the present study. Again, the circumscribed 'catch-all' Asian genus Mycalesis was recovered as a polyphyletic group just as in Kodandaramaiah and colleagues [30]. However, we recovered the sampled Mycalesis (sensu lato) taxa as three and not the four distinct clades previously reported. Kodandaramaiah et al. [30] found two Asian (Heteropsis) clades, (Heteropsis

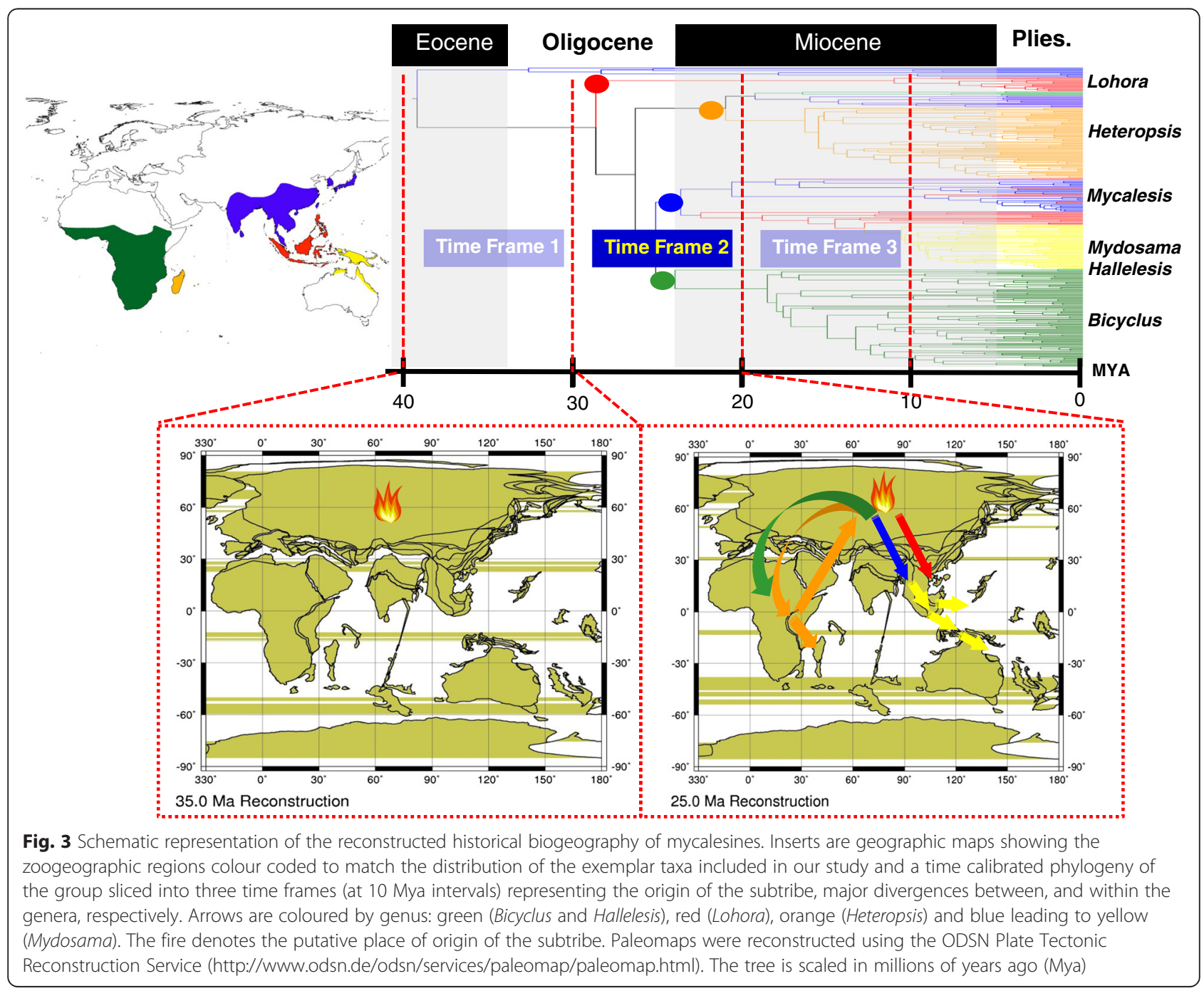


adolphei) and $(H$. sangaica $+H$. mamerta $+H$. malsara $+H$. janardana), nested within the Afro-Malagasy clade but in a polyphyletic fashion. We recovered all the Asian Heteropsis taxa as a single well-supported clade inside the Afro-Malagasy clade.

\section{Mycalesis, Mydosama and Culapa}

As clearly shown in the results, most of the Asian and Australasian taxa segregated into two major clades, supporting an earlier suggestion by Kodandaramaiah and colleagues [30] to split the currently circumscribed Mycalesis into at least two genera. One clade, referred to here and in Kodandaramaiah et al. [30] as Mycalesis sensu stricto contains the type species of the genus (Papilio francisca) and 36 other taxa occurring predominately on subcontinental India, Indo-China and marginally into Sundaland. Interestingly, many taxa of this clade that occur in Sundaland are only represented in the Western part (i.e., Peninsular Malaysia), closest to the Asia/Indo-China mainland. We support an earlier proposal to classify this clade as Mycalesis sensu stricto. The other clade, referred to here and in Kodandaramaiah et al. [30] as Mydosama, is nearly allopatric with Mycalesis. Taxa of this clade largely include mycalesine species distributed in Sundaland, the Philippines and the Australasian regions. Kodandaramaiah et al. [30] suggested this clade be transferred to Mydosama, Moore 1880, which has the type species, M. fuscum Felder and Felder 1860. However, with the inclusion of M. mnasicles as part of this clade in our reconstruction, the name Mydosama may not be appropriate (potentially junior), as it post-dates the name Culapa Moore, 1878, which has Dasyomma mnasicles as the type species. From our phylogeny, the taxa Mycalesis mnasicles and M. amoena are retrieved as sister to all taxa of Mydosama. M. mnasicles is currently distributed in Indo-China and marginally into Sundaland. M. amoena is however restricted in distribution range to forests in Borneo.

Given the unique morphology of $M$. mnasicles and $M$. amoena, coupled with the moderate to weak support in the ML topology ( $\mathrm{BS}=51 \%, \mathrm{PP}=0.98)$ for their sisterrelationship with the rest of Mydosama, we split off the taxa M. mnasicles and M. amoena and classify them as a separate genus. With this approach, both Culapa and Mydosama can be brought into use while promoting stability within this rather complex species group. The taxon sampling in Asia is relatively low in our study compared to that in Africa and Madagascar. Thus we have sampled $\sim 68 \%$ of all recognised mycalesines in Asia in the current study compared to $\sim 82 \%$ in the Afro-Malagasy region. It would therefore not be surprising if increased sampling in Asia revealed more members of the genus Culapa, or even additional distinct lineages or genera within mycalesines in the region. Culapa was described as a monotypic genus by Moore [12]. But as has been shown in our study, many of the original taxa described by Moore on the basis of adult morphology as monotypic genera (e.g. M. maianeas as Satoa Moore, 1880, M. orseis as Suralaya Moore, 1880, M. adolphei as Telinga Moore, 1880, M. oroatis as Loesa Moore, 1880) are not entirely accurate; rather they have closely related sister species. It is worth noting that Moore's classification was solely based on androconia (or scent-producing organs as he called them) and wing shape. Previous studies have shown the problems such as homoplasy that result in the use of a few morphological characters that are not under relatively neutral selection in such classifications [13, 32]. We are of the view that a detailed molecular investigation of the mycalesines in Asia will help refine our knowledge on their rather complex morphology and, ultimately, their systematics.

\section{Heteropsis}

This is the only genus that has representations in all the major paleotropical regions, according to the phylogenetic hypothesis presented in this study. Our proposed framework provides support for monophyly of each of the Heteropsis species groups on the different continents or islands. Whilst the numbers of Heteropsis species in the Malagasy region and mainland Africa is estimated at around 75 and 13 respectively, the richness in Asia is unknown because mycalesines in this region have also been treated broadly as Mycalesis in which a large number of names exist for different island and mainland populations. Kodandaramaiah et al. [30] recovered five Mycalesis species (treated here as $H$. adolphei, $H$. sangaica, $H$. mamerta, $H$. malsara, and $H$. janardana) as belonging to the Heteropsis clade, one of which, $H$. adolphei, has earlier been suspected to be within this genus based on genital morphology [13]. In the present study we recovered, in addition to the above five taxa, three additional Asian taxa (H. oculus, H. inopia, and H. nicotia/misenus) clustering within this largely Indian Heteropsis clade. This wellsupported Indian Heteropsis clade $(\mathrm{BS}=99, \mathrm{PP}=1)$ was nested within the Afro-Malagasy Heteropsis clade.

Two of the sampled Mycalesis taxa (here treated as Asian Heteropsis), H. janardana and H. sangaica, have long been considered as a separate species-group since Moore [12] described them as belonging to the genus Martanda Moore, 1880, together with the then taxon M. megamede Hewitson, [1862] (which was later found to be a junior synonym of $M$. janardana). With the exception of $H$. oculus and $H$. adolphei, all the remaining sampled Asian Heteropsis are categorised according to Aoki et al. [28] as belonging to one informal subgeneric unit called species-group 3 . It is very likely from morphology that, the (molecularly) unsampled members of Aoki and colleagues' [28] species group 3 (M. heri, M. 
mestra, M. misenus, M. annamitica, M. lepcha) belong the Asian Heteropsis clade. However, we are uncertain in the case of $M$. suaveolens, that was also included by Aoki et al. [28] in this group, as it lacks the typical irrorated pattern of the ventral wing surfaces of species in this group. $H$. oculus was similarly misplaced in the species group 2 of Aoki et al. [28], together with Mycalesis taxa such as $M$. perseus, $M$. mineus, $M$. visala and $M$. perseoides. The latter were recovered as part of clade Mycalesis I or Mycalesis sensu stricto [30]. We also confirm that $H$. oculus is most closely related to Satyrus adolphei (type species of Telinga, Moore, 1880) which occurs on the other side of the Palghat Gap [4]. At the moment, $H$. oculus (and by association $H$. adolphei) seems to be the only Asian Heteropsis taxon 'wrongly' placed in the subgeneric classification of Aoki et al. [28]. However, it is still unclear how many of the unsampled Mycalesis species in the different species-groups of Aoki et al. [28] actually belong to the Asian Heteropsis clade. Here, we reiterate the importance of a more comprehensive molecular and morphological study of the mycalesines in this region.

According to our phylogenetic hypothesis, the relationships among the Afro-Malagasy Heteropsis species were not consistent with subgeneric classification proposed in Lees [13] and Lees et al. [19]. For instance, the hierarchically reciprocal monophyly of each Heteropsis clade on the different continents in the present study suggests that the currently circumscribed subgenera Telinga and Henotesia, which include taxa occurring in and outside the Malagasy region in some treatments [21-23] are incorrect. About a third of the total mycalesine fauna in Madagascar are currently being described as new (D. C. Lees, submitted). It will be useful to include samples of these newly described taxa in a detailed molecular study that holistically explores the intricate evolutionary history of this widely distributed butterfly group across the Old World tropics.

\section{Lohora}

As shown in our results, the two species of the subsumed genus Nirvanopsis Vane-Wright, 2003 (N. susah and $N$. hypnus) are clearly nested within Lohora as was also found by Kodandaramaiah et al. [30]. The relationship among Lohora species is highly consistent with the three recognised subgeneric divisions [14] which could therefore be retained if required. A clade comprising $L$. erna, L. imitatrix and L. inga in our tree represented the subgenus Physcon de Nicéville, 1898, which has five other taxa ( $L$. decipiens, $L$. umbrosa, $L$. deianira, $L$. deianirina and $L$. pandaea) that were not sampled in our study. Six of the seven described species of the nominate subgenus Lohora Moore, 1880 clustered in our tree as a wellsupported clade. The monotypic subgenus Pseudomycalesis
Tsukada and Nishiyama, 1979, currently consisting of only L. tanuki, should however be redefined or expanded to include the two taxa of the junior genus Nirvanopsis, to reflect our phylogeny. This proposed redefinition of Pseudomycalesis is also supported by the superficial similarities in their genitalic morphology and eye-spot patterns on the hind wings [14].

\section{Bicyclus and Hallelesis}

The African genera, Bicyclus and Hallelesis, are the only mycalesines that lack conspicuous hairs on their compound eyes. From our proposed phylogenetic framework, it appears that this interommatidial setal trait was lost in Africa, where these genera are inferred to have split, and since no other naked eye mycalesines are known in Africa. Members of Hallelesis and Bicyclus were regarded as a single genus until Condamin [33] separated them based on the single character of the presence of long scent-producing hair-tufts in the male genitalia of the former. A stronger and more convincing justification for the generic separation is provided by the present and by past studies based on molecules [30, 31], as well as by morphological studies of immature stages [34] of African mycalesines.

Nevertheless, the phylogenetic position of these two African endemic clades in the entire mycalesine radiation has not been resolved previously. Although Bicyclus and Hallelesis are similar in terms of life history traits [34] and are often seen flying together in the wild [35], previous molecular studies (albeit with weak nodal supports) found the latter genus to be more closely related to either Heteropsis [18, 31], or to the Oriental Mycalesis [30]. The relationship of Bicyclus to other mycalesines has also never been strongly established. Kodandaramaiah and colleagues [30] without strong support, retrieved Bicyclus as the sister taxon to all mycalesines, a hypothesis that has fundamental implications for the origin of the entire subtribe. Including just two exemplar taxa of Bicyclus in their study of mycalesines in Madagascar, Torres et al. [18] recovered it without strong support as a nested clade within the Malagasy Heteropsis. The latter authors, however, admitted this relationship might be an artefact of their poor taxon sampling of Bicyclus. Based on our present study, we consider Hallelesis and Bicyclus as sister clades with a common ancestor derived from Asia. Hallelesis, that we still consider as a different genus, diverged long ( 24 Mya) before the diversification of Bicyclus into its extant taxa. The similarity in life history traits in the immature stages [34] and the coexistence of the adults of Hallelesis and taxa of the basal clade of Bicyclus (evadne species-group) in the wild [35] further strengthens our hypothesis that the two genera are sister taxa. 
In general, the relationships between the major mycalesine lineages or genera are reasonably stable and congruent among the different methods. In the light of a relatively well resolved backbone topology in the current phylogenetic hypothesis, we next discuss the implications of these findings for our understanding of the historical biogeography of Mycalesina.

\section{Historical biogeography}

Our ancestral range estimation methods clearly point to present-day Asia as the area of origin of the subtribe Mycalesina. We hypothesise that the common ancestors of Mycalesina and Lethina were distributed in Eurasia during the Oligocene until they split around 38 Mya. This hypothesis is further strengthened by the discovery of a fossil (Lethe corbieri) of the mycalesine putative sister group Lethina [36] in Oligocene deposits of south eastern France [37]. A vicariance event is hypothesised to be responsible for the first split between the Moluccan Lohora and the rest of Mycalesina, although oceanic dispersal is not completely ruled out [38]. Until the Eocene epoch, all islands in the western Pacific Ocean (including those on the Sundaland and Asian islands) were putatively part of the 'supercontinent' Asia [38-41]. This contiguous landmass is believed to have facilitated faunal movements and gene flow among different populations in the region at that time.

However, the gradual formation of the Makassar Strait (between present-day Borneo and Sulawesi) in the Eocene is thought to have severed the land connection [38, 40, 42]. Available paleontological evidence suggests that by the middle of the Miocene, most of the land of proto-Sulawesi had disappeared below sea-level, leaving only a small part of the island until the mid-Miocene $[42,43]$. The Makassar Strait is implicated to have caused a disjunction and a physical barrier to biotic exchanges or gene flow between the common ancestors of all extant mycalesines on the mainland Asian and Sulawesi at the time. This implied Paleogene vicariance event is not only peculiar to the historical biogeography of Lohora. In their comprehensive review of butterflies on Sulawesi, Vane-Wright and de Jong [29] found an exceptionally high number of endemics at the species level (>40\%). This was in stark contrast to the level of endemism at the genus level. Almost all the genera (>95\%) on the island have representatives on the mainland Asia, with no special relationship with Borneo which is just $120 \mathrm{~km}$ away from Sulawesi [29, 44]. This observation suggests that most of the butterflies on Sulawesi and its satellite islands might have resulted from an older vicariance or from isolation events, rather than recent dispersals from closer islands or landmasses to the island.
Although these authors [29, 44] found signatures of an older biogeographic event in Sulawesi butterflies, they could not explicitly implicate vicariance as a plausible explanation of what they describe as the "basic puzzle of Sulawesi butterfly fauna" because of the absence of a time-calibrated phylogeny for most species groups at the time. The present study supports the case of a possible Paleogene vicariance event resulting in the Sulawesi endemic mycalesine group Lohora. The divergence of Lohora from the other mycalesines apparently occurred around 28 Mya (Fig. 2), although the genus only began to diversify some 11 Mya (HPD, 8.3-13.25 Mya), roughly when Sulawesi is thought to have started to expand its land mass. Currently, there are 19 described Lohora (sensu lato) species (two of which were earlier placed in Nirvanopsis) and all are confined to forests of differing types and bioclimatic conditions in Sulawesi [14].

A single species, L. susah, is restricted to Taliabu, a Pleistocene landbridge island east of the Sulas [45]. Müller and Beheregaray [46] report a similar time of divergence (ca. 26 Mya) between the Sulawesi lacewing butterflies Cethosia and their congenerics on mainland Asia. A similarly older vicariant event is implicated in the split between the Charaxes butterflies on the Wallacea and those in other regions in Asia [47]. Some recent molecular phylogenetic studies of Sulawesi taxa such as Chitaura grasshoppers [48], wood-feeding cockroaches [49] and mite harvestmen [50] identified Asia as their origin and suggested vicariance as the likely mechanism for the current distribution of the taxa on the island. It remains to be seen whether similar results will be found in other more species rich groups on the island. The only endemic Mycalesis species in Sulawesi, $M$. itys, is estimated to have diverged from its sister group in the Miocene ca. 14 Mya.

Kodandaramaiah and his colleagues [30] postulated that there has been at least one dispersal event between Africa and Asia. However, they could not infer the direction of such colonisation event due to their inability to distinguish between hypotheses of African and Asian origin for the subtribe, combined with a poorly supported basal relationship in their phylogenetic hypothesis. With the well resolved basal relationships in the current study, we infer at least two events of dispersal of ancestors from Asia to Africa and a later back colonisation of Asia by African ancestors. These dispersal events are dated between 26 and 19 Mya and coincide with the period when Afro-Arabia and Eurasia putatively collided around the Arabian Peninsula [51, 52]. The collision of the Afro-Arabian plates with Eurasia, in the early Miocene, caused the emergence of a terrestrial corridor, called the "Gomphotherium" Landbridge [53]. This putative land bridge is believed to have facilitated faunal exchanges between Africa and Eurasia in the Miocene, 
as reported in the butterflies Junonia [54] and Charaxes [55], as well as mammals [52, 56], reptiles [57, 58] and many other organisms. We surmise that the ancestors of mycalesines used this corridor which is thought to have been forest-covered in the Miocene [60]. The subsequent separation of Afro-Arabia and the Indian subcontinent, following the marine connections between the Mediterranean Sea, Indian Ocean and the Paratethys in the mid-Miocene [54] may have partitioned the distribution of mycalesines between the two continents.

The first colonisation event by Asian ancestors to Africa is inferred to have given rise to Heteropsis on mainland Africa, which probably dispersed into Madagascar via oceanic dispersal. The ancestral area analyses however, suggest Asia, Africa or both as the origin of the Malagasy Heteropsis. The lack of resolution on the origin of Malagasy Heteropsis is largely due to the well supported and reciprocal monophyly of the Asian and African Heteropsis clades. If Madagascar was indeed colonised from Africa it might be more closely related to some as yet unsampled lineage there. Perhaps including more exemplar taxa of currently unsampled African and Asian taxa, could help refine our understanding on the origin, although a range-constrained analysis in LAGRANGE suggested Africa as the most likely source of Malagasy Heteropsis. The second colonisation of Africa by Asian mycalesines is also estimated to have happened in the Oligocene. This event is inferred to have resulted in the African genera Hallelesis and Bicyclus, neither of which could back-colonise Asia nor disperse successfully to Madagascar. B. anynana is found on the island of Grande Comoro and on Socotra, but these are recent colonisation events which have not yet resulted in local speciation.

All the ancestral area reconstruction methods identified Asia as the area of origin for Mycalesis, Culapa and Mydosama. The splits between these Asian clades are estimated to have occurred at the Oligocene-Miocene boundary (23 Mya). According to our reconstruction, the most recent common ancestors of the resurrected genus Mydosama were most likely distributed on Borneo and other Southeast islands such as Sulawesi and Philippines that fractured off mainland Asia between the Oligocene and Miocene. The extant species of Mydosama mainly occur on the Wallacean and Australasian regions. The age of split between the Wallacean and Australasian species groups is estimated at 11 Mya. This time of divergence corresponds, or immediately follows, the orogeny of New Guinea and other neighbouring islands. Dispersal into new regions created new ecological opportunities which presumably flattened the adaptive landscape, facilitating a sudden burst in the diversification $[59,60]$.

\section{Conclusion}

The current study presents the most extensive molecular phylogenetic species-level analysis of mycalesines to date. We have substantially clarified the taxonomy of the group in this study and laid the path towards stabilising the frequent higher-level taxonomic changes associated with the group. Asia is identified as the ultimate area of origin of the subtribe Mycalesina and the crown age of the group is estimated as 40 Mya. We have also established, with strong support, the phylogenetic relationships of the different mycalesine groups across the Old World tropics and proposed the most robust narrative of the biogeographic history of the group to date. The current study paves the way for studies aimed at understanding the fundamental evolutionary mechanisms that operate on large temporal and spatial scales in species radiations. Thus, our time-calibrated tree sets the stage for comparative analyses of the tempo and mode of diversification of the different parallel radiations within the subtribe. Our proposed phylogeny serves as a guide for future studies aiming to extrapolate the numerous population level studies within the model species, Bicyclus anynana to closely related taxa. Researchers are now in the position to unravel the causes of the spectacular adaptive radiation of mycalesines in the Old World tropics.

Based largely on the molecular evidence provided in this study and some morphological evidence we recommend the following generic classification within the subtribe Mycalesina Reuter, 1896.

Genus Lohora Moore 1880. Type species, by original designation: Mycalesis dexamenus Hewitson, 1862.

Genus Heteropsis Westwood, 1850. Type species, by original designation: Heteropsis drepana Westwood, [1850].

Genus Mycalesis Hübner, [1818]. Type species, designation: Papilio francisca Stoll, [1780].

Genus Mydosama Moore, 1880. Type species (replacement name of Dasyomma C. \& R. Felder, 1860, preocc): Dasyomma fuscum C. \& R. Felder, 1860.

Genus Culapa Moore, 1878. Type species, by original designation: Mycalesis mnasicles Hewitson, [1864].

Genus Bicyclus Kirby, 1871. Type species (replacement name for Idiomorphus Doumet, 1861, preocc.): Idiomorphus hewitsoni Doumet, 1861.

Genus Hallelesis Condamin, 1961. Type species, by original designation: Mycalesis asochis Hewitson, 1866.

\section{Methods}

\section{Taxon sampling}

A total of 185 samples representing all current genera and almost all species groups of Mycalesina across their distributional range were collected either by the authors during field expeditions between 2011 and 2014 or by 
numerous collaborators (see Acknowledgements). Noticeable exceptions are a few species that might well form monospecific groups but for which useful sequences could not be obtained (M. aramis, M. nala, $M$. suaveolens, and $M$ unica). Samples for DNA extraction were usually one or two legs, and in a few cases, thoracic tissue of dried mounted vouchers or ethanol-preserved specimens. As outgroups, 10 exemplar taxa were carefully selected using the most recent comprehensive phylogeny of the family Nymphalidae [61]. Genomic DNA was extracted using the Qiagen DNEasy extraction kit, following the guided protocol by the manufacturer. A total of ten molecular markers; one mitochondrial (cytochrome c oxidase subunit I, CO1) and nine nuclear (carbamoylphosphate synthetase domain protein, CAD; Ribosomal Protein S5, RpS5; Ribosomal Protein S2, RpS2; wingless, wgl; cytosolic malate dehydrogenase, $\mathrm{MDH}$; glyceraldehyde-3-phosphate dehydrogenase, GAPDH; Elongation factor 1 alpha, EF-1 $\alpha$; and Arginine Kinase, ArgKin and Isocitrate dehydrogenase, IDH) gene regions were amplified and sequenced for each of the exemplar taxa using primer-pairs obtained from Wahlberg and Wheat [62].

Successful amplicons were cleaned with EXO-SAPIT (Affymetrix) and sent to Macrogen Services (Amsterdam) for Sanger sequencing. DNA sequences and, where possible, aliquots of DNA extracts used in previous mycalesine studies (e.g. Monteiro and Pierce, Kodandaramaiah et al. [31]) were also obtained from the authors and included in the present study. Nucleotide sequence alignment was done by eye using Bioedit [65]. Sequences were then managed and datasets constructed using Voseq v1.7.4 [66]. The software MEGA v6 [67] was used to assess the properties of the sequences of individual genes and the multi-gene concatenated sequence matrix.

\section{Phylogenetic inference}

To minimise the effect of saturation and also improve phylogenetic resolution of our multi-gene dataset, PartitionFinder v1.1.1 [63] was employed to select the optimal gene partitioning schemes and the best-fit model of nucleotide substitution for each partitioned dataset, under the Bayesian Information Criterion (BIC). To check for the degree of congruence among the different markers, phylogenetic analyses were done first separately for each gene (producing gene trees) and later for all the ten genes combined, but partitioned by the optimal gene partitioning scheme suggested by PartitionFinder analyses. Phylogenetic inference analyses were carried out using both Maximum likelihood (ML) and Bayesian Inference (BI) methods.

Maximum likelihood phylogenetic inference analyses was implemented in RAxML-HPC2 v8.0.24, on the
CIPRES Science Gateway v3.3 [64], using the partition scheme from the PartitionFinder analysis (Additional file 2: Table S2), under the GTRCAT model for the rapid bootstrapping phase, and GTRGAMMA for the final best scoring ML tree. For bootstrapping, we performed 1000 Maximum Likelihood (ML) pseudo-replicates analyses. Bootstrapping was performed under auto Majority Rule Criterion (autoMRE). BI was carried out using Markov Chain Monte Carlo (MCMC) randomisation in MrBayes v3.2 [65]. We used reversible-jump MCMC to allow for sampling across the entire substitution rate model opposed to specifying one substitution model suggested by PartitionFinder in this analysis. Two parallel runs of four chains ( 3 heated and 1 cold) were performed for 50 million generations, with sampling done at every $5000^{\text {th }}$ generation. The software Tracer v1.6 [66] was used to inspect the sample sizes of the parameters used in the BI and also check for the convergences or otherwise of the parallel MCMC runs.

\section{Estimating times of divergence}

Times of divergence within Mycalesina were estimated using a Bayesian MCMC approach in BEAST 2, v2.1.2 [67]. Tree calibrations were done using two secondary age calibration points from Wahlberg et al. [61] and one fossil, Lethe corbieri, found in the Oligocene deposits of southeast France [37]. It is important to point out that these two approaches are not entirely independent as Wahlberg et al. [61] used Lethe corbieri and six other fossils in their divergence-time estimation. Based on Wahlberg et al. [61], the stem age of the subtribe Mycalesina was constrained to be $40 \pm 5.5$ Million Years Ago (Mya) with a normal distribution prior between the minimum and maximum age bounds. The second calibration point was the crown age of all mycalesines, excluding Lohora, and this was constrained to be $26.6 \pm 4.5$ Mya. It is worth noting that Wahlberg et al. [61] did not include an exemplar taxon of Lohora in their study. Lohora was recovered as sister to all other mycalesines in our estimate of phylogenetic relationships. Using the estimated age of the Lethe corbieri fossil, the minimum age (or offset) of the divergence between Lethe and its sister group was constrained at 25 Mya, under an exponential distribution prior.

We implemented a birth-death process with an uncorrelated log-normal distribution model for lineage substitution rate variation. The summarised tree produced using MrBayes was used as the starting tree in the XML file generated using BEAUTi (which is part of the BEAST package). The MCMC chain was run for 50 million generations, with 2 independent runs. The resultant BEAST log files were viewed in Tracer v1.6 [66] to inspect ESS of the parameters and points of convergence. With a threshold of $25 \%$ burn-in, all post burn-in trees 
from the 4 independent runs were combined using the software LogCombiner v2.1.2 [67]. TreeAnnotator v2.1.2 [67] was used to summarise information (i.e., nodal posterior probabilities, posterior estimates and highest posterior density, HPD limits) from the individual post burn-in trees onto a single Maximum Clade Credibility (MCC) tree. The summarised information were visualised on the MCC tree using FigTree v1.4 (http://tree.bio.ed.ac.uk/software/figtree/). To assess the impact of different tree-shape and clock priors on our results [68], we repeated the analysis with yule and calibrated-yule models of speciation, under both normal and uniform distribution priors between the minimum and maximum age bounds calibration points. There was no significant difference among the results (Additional files 5: Table S4).

\section{Ancestral range estimation or reconstruction}

Ancestral range estimation or reconstruction analyses were done using 100 randomly selected ultrametric trees generated from the BEAST analyses. Ancestral state reconstruction or estimation was done using both as a dispersal-extinction-cladogenesis (DEC) analysis in LAGRANGE [69, 70] and S-DIVA [71]. Both analyses were implemented in RASP [72] and required ultrametric trees and the present distribution of the extant taxa as input files.

Following Proches and Ramdhani [73], the current distributional range of mycalesines was divided into five zoogeographical clusters: 1. Afrotropics (which denotes mainland Africa, south of the Sahara); 2. Malagasy Region (encompasses Madagascar and the surrounding Mascarene islands in the Indian Ocean); 3. Continental Asia (includes the Indian subcontinent, Indo-China); 4. Wallacea (archipelagic transitional zone between Indo-Malaysian, Australian Regions and New Guinea, which includes Sulawesi, Philippines and Moluccas). 5. Australasian Region (covers New Guinea, Solomon Islands archipelago, tropical Australia), Using the present distribution of the extant taxa, each exemplar taxon in the tree was categorised into one or more of the five defined zoogeographic regions.

DEC analyses were carried under two scenarios; (1) unconstrained (where dispersal among all possible pairwise geographic areas are permitted) and (2) constrained (where we defined, a priori, the dispersal probability and area-connectivity between geographic areas, using our knowledge of the system). The connectivity matrix for the DEC analyses are in Additional file 6: Table S5. Probabilities to disperse were set to 1 for pairs of areas separated by at least $400 \mathrm{~km}$ of water (e.g. Africa and Madagascar, Africa and Asia, Asian and Wallacea, Wallacea and Australasian Region), to 0.1 when two areas were separated by water of a distance less than $3000 \mathrm{~km}$ (e.g. Asia and Madagascar), 0.001 and 0.0000001 for long- distance dispersal and highly unlikely scenarios, respectively (e.g. Madagascar and Wallacea, Africa and New Guinea).

\section{Ethical approval}

The funders of the project, European Research Council (ERC) approved the ethics and methods employed in the conduct of the study.

\section{Availability of supporting data}

The data sets supporting the results of this article will be made available in the TreeBASE repository, in http:// treebase.org/treebase-web/home.html. Sequences will be submitted to Genbank with accession numbers made available in the final manuscript.

\section{Additional files}

Additional file 1: Table S1. List of exemplar mycalesines taxa included
in the study and the gene regions amplified and sequenced per taxon.
" $\mathrm{X}$ " denotes a case where a gene region was successfully amplified and
sequenced for the taxon. Gene regions (COI, Ef1a, MDH, CAD) more than
800 base pairs long were amplified in two parts. (XLSX $35 \mathrm{~kb})$

Additional file 2: Table S2. The PartitionFinder estimated best-fit partitioning schemes and models of molecular evolution of Mycalesina data matrix used in the RaxML tree estimation analysis. The best model was selected under a Bayesian Information Criterion (BIC). (DOCX 20 kb)

Additional file 3: Table S3. The estimated mean values and Effective Sample Sizes of parameters used in the BEAST time of divergence analyses. The figures are combined values of three independent BEAST Monte Carlo Markov Chain analyses, each ran for 50 Million generations. (XLSX $14 \mathrm{~kb}$ )

Additional file 4: Figure S1. Phylogenetic relationships of the different genera within the subtribe Mycalesina estimated using RaxML maximum likelihood method. A consensus phylogeny is shown using the combined 10 genes dataset. The numbers besides the nodes are the bootstrap support values. (PDF 82 kb)

Additional file 5: Table S4. BEAST priors sensitivity test. Comparison of time of divergence at 40 nodes selected across different parts of the Mycalesina tree, using different tree-shape (birth-death, yule, calibrated-yule) and clock (normal and uniform) priors. (XLSX 29 kb)

Additional file 6: Table S5. Geographic connectivity matrix and the $a$ priori dispersal probability constraints used for the constrained dispersal-extinction-cladogenesis (DEC) analysis. (DOCX 14 kb)

\section{Abbreviations}

Mya: Million years ago; ML: Maximum likelihood; Bl: Bayesian Inference; PP: Posterior probabilities; MCC: Maximum Clade Credibility; HPD: Highest posterior density; ESS: Effective sample sizes; MCMC: Markov Chain Monte Carlo; BIC: Bayesian Information Criterion.

\section{Competing interests}

The authors declare that they have no competing interests.

\section{Authors' contributions}

KAP, UK, PMB and NW conceived the idea. KAP, DCL, UK and OB provided the bulk of the samples for the study. KAP performed most of the lab work. KAP and NW analysed the data. The manuscript was drafted by KAP with active participation from the rest of the authors. All authors read, corrected and approved the final manuscript. 


\section{Acknowledgements}

We are grateful for the numerous contributions from and assistance by the following persons and institutions; Steve Collins, African Butterfly Research Institute (ABRI) Nairobi, Chris Muller, Szabolcs Sáfián, David Lohman, Andrew Rawlins and K. Praveen Karanth. We thank Ghana Wildlife Division and Madagascar National Parks Association (PNM-ANGAP) for granting us permission to collect specimen in Ghana and Madagascar respectively. A few photos were taken by Harry Taylor (copyright courtesy of trustees of Natural History Museum). Financial support for this study was provided by an ERCEMARES (\#250325) grant awarded to PMB. NW thanks the Academy of Finland for support, and UK acknowledges support through the DST INSPIRE Faculty Award.

\section{Author details}

Department of Zoology, Radiating Butterflies Group, University of Cambridge, Downing Street, Cambridge CB2 3EJ, UK. ${ }^{2}$ School of Biology, Indian Institute of Science Education and Research Thiruvananthapuram (IISER-TVM), CET campus, Sreekaryam, Thiruvananthapuram Kerala 695016, India. ${ }^{3}$ Department of Biology, NSG, Laboratory of Genetics, University of Turku, Turku 20014, Finland.

\section{Received: 3 June 2015 Accepted: 6 August 2015} Published online: 20 August 2015

\section{References}

1. Brakefield PM. Radiations of mycalesine butterflies and opening up their exploration of morphospace. Am Nat. 2010;176:S77-87.

2. Kremen C. Biological inventory using target taxa - a case-study of the butterflies of Madagascar. Ecol Appl. 1994;4(3):407-22.

3. Fermon $\mathrm{H}$, Waltert M, Vane-Wright RI, Muhlenberg M. Forest use and vertical stratification in fruit-feeding butterflies of Sulawesi, Indonesia: impacts for conservation. Biodivers Conserv. 2005;14(2):333-50.

4. Sekar S, Karanth P. Flying between sky islands: the effect of naturally fragmented habitat on butterfly population structure. PLoS One. 2013;8(8):e71573.

5. Aduse-Poku K, William O, Oppong SK, Larsen T, Ofori-Boateng C, Molleman F. Spatial and temporal variation in butterfly biodiversity in a West African forest: lessons for establishing efficient rapid monitoring programmes. Afr J Ecol. 2012;50(3):326-34.

6. Beldade P, Koops K, Brakefield PM. Developmental constraints versus flexibility in morphological evolution. Nature. 2002;416(6883):844-7.

7. Brakefield PM, Gates J, Keys D, Kesbeke F, Wijngaarden PJ, Monteiro A, et al. Development, plasticity and evolution of butterfly eyespot patterns. Nature. 1996;384(6606):236-42

8. Oostra V, Brakefield PM, Hiltemann Y, Zwaan BJ, Brattstrom O. On the fate of seasonally plastic traits in a rainforest butterfly under relaxed selection. Ecol Evol. 2014:4(13):2654-67.

9. van Bergen E, Brakefield PM, Heuskin S, Zwaan BJ, Nieberding CM. The scent of inbreeding: a male sex pheromone betrays inbred males. Proc $R$ Soc B Biol Sci. 2013;280(1758):20130102

10. Condamin M. Monographie du Genre Bicyclus (Lepidoptera: Satyridae). Institut Fondamental d' Afrique Noire, IFAN: Dakar; 1973.

11. Miller LD. The higher classification, phylogeny and zoogeography of the Satyridae (Lepidoptera). Memoirs Am Entomol Soc. 1968;24:174.

12. Moore F. XIII. On the Asiatic Lepidoptera referred to the genus Mycalesis, with descriptions of new genera and species. Trans Royal Entomol Soc Lond. 1880:28(4):155-78.

13. Lees DC. Systematics and Biogeography of Madagascan Mycalesine Butterflies (Lepidoptera: Satyrinae). London: PhD Thesis, University of London; 1997

14. Vane-Wright Rl, Fermon H. Taxonomy and identification of Lohora Moore (Lepidoptera : Satyrinae), the Sulawesi bush browns. Invertebr Syst. 2003;17(1):129-41

15. Condamin M. Lépidoptères Hesperiidae récoltés au Cameroun par C de Raemy. Bulletde I'Institut Français d'Afrique Noire. 1960;A(22):919-23.

16. Larsen TB. The butterflies of Kenya and their natural history. Oxford: Oxford University Press; 1991.

17. Williams MC. Afrotropical Butterflies and Skippers. In: A digital encyclopaedia. Rietondale: http://www.atbutterflies.com/; 2014.

18. Torres E, Lees DC, Vane-Wright RI, Kremen C, Leonard JA, Wayne RK. Examining monophyly in a large radiation of Madagascan butterflies
(Lepidoptera : Satyrinae : Mycalesina) based on mitochondrial DNA data. Mol Phylogenet Evol. 2001;20(3):460-73.

19. Lees DC, Kremen C, Raharitsimba H. Classification, diversity and endemism of the butterflies (Papilionoidea and Hesperioidea): a revised species checklist. In: Goodman SM, Benstead JP, editors. The natural history of Madagascar. Chicago: University of Chicago Press; 2003. p. 1709.

20. Kielland J. A revision of the genus Henotesia excluding Madagascar and other Indian Ocean Islands Lepidoptera Satyridae. Lambillionea. 1994:94(2, 1):235-74.

21. Libert M. Note sur le genre Henotesia Butler, (Lepidoptera, Satyridae). Lambillionea. 2006;106(2):167-80.

22. Fruhstorfer $\mathrm{H}$. Neue indo-australische Mycalesis und Besprechung verwandter Formen. Verhandlungen der Kaiserlich-Königlichen ZoologischBotanischen Gesellschaft in Wien. 1908;58:126-239.

23. Karsch F. Die Insecten de Bergenlandschaft Adeli im Hinterlande von Togo (Westafrika). Berliner Entomologische Zeitschrift. 1893;38:1-266.

24. Evans WH. A Note on the species of the genus Mycalesis (Lepidoptera), occurring within Indian limits. J Bombay Nat Hist Soc. 1920;27:354-62.

25. Peña C, Wahlberg N. Prehistorical climate change increased diversification of a group of butterflies. Biol Lett. 2008;4(3):274-8.

26. Peña C, Wahlberg N, Weingartner E, Kodandaramaiah U, Nylin S, Freitas AVL, et al. Higher level phylogeny of Satyrinae butterflies (Lepidoptera : Nymphalidae) based on DNA sequence data. Mol Phylogenet Evol. 2006:40(1):29-49.

27. Vane-Wright RI. Systematics of Drusillopsis oberthur (Satyrinae) and supposed Amathusiid Bigaena van Eecke (Lepidoptera - Nymphalidae), with some observations on batesian mimicry. Trans Royal Entomol Soc Lond. 1971;123:97.

28. Aoki T, Yamaguchi S, Uemura Y. Vol.III. Satyridae, Amathusiidae and Libytheidae: Butterflies of the South East Asian Islands, vol. 3. PlapacTsukada E: Tokyo; 1982

29. Vane-Wright $R$, de Jong R. The butterflies of Sulawesi: annotated checklist for a critical island fauna. Verhandlungen der Zoologisch. 2003;343:267.

30. Kodandaramaiah U, Lees DC, Müller CJ, Torres E, Karanth KP, Wahlberg N. Phylogenetics and biogeography of a spectacular Old World radiation of butterflies: the subtribe Mycalesina (Lepidoptera: Nymphalidae: Satyrini). BMC Evol Biol. 2010;10:172

31. Monteiro A, Pierce NE. Phylogeny of Bicyclus (Lepidoptera : Nymphalidae) inferred from COI, COII, and EF-1 alpha gene sequences. Mol Phylogenet Evol. 2001;18(2):264-81.

32. Kohler F, Criscione F. A molecular phylogeny of camaenid land snails from north-western Australia unravels widespread homoplasy in morphological characters (Gastropoda, Helicoidea). Mol Phylogenet Evol. 2015;83:44-55.

33. Condamin M. Mises au point de synonymie et descriptions de nouveaux Bicyclus (Lepidoptera Satyridae). Bulletin de l'Institut Français d'Afrique Noire. 1961;A(23):782-99.

34. Sourakov A, Emmel TC. Bicyclus and Hallelesis: Their immature stages and taxonomic relationships (Lepidoptera: Nymphalidae: Satyrinae). Tropl Lepida. 1997:8 Suppl 3:14-22.

35. Larsen TB. Butterflies of West Africa. Stenstrup: Apollo Books; 2005

36. Peña $C$, Nylin $S$, Wahlberg $N$. The radiation of Satyrini butterflies (Nymphalidae: Satyrinae): a challenge for phylogenetic methods. Zool J Linn Soc. 2011;161(1):64-87.

37. Nel A, Nel J, Balme C. A new fossil Lepidoptera Satyrinae from the Oligocene of south-eastern France (Insecta, Lepidoptera, Nymphalidae). Linneana Belgica. 1993;14(1):20-36.

38. Stelbrink B, Albrecht C, Hall R, von Rintelen T. The Biogeography of Sulawesi Revisited: Is there Evidence for a Vicariant Origin of Taxa on Wallace's "Anomalous Island"? Evolution. 2012;66(7):2252-71.

39. de Bruyn M, Stelbrink B, Morley RJ, Hall R, Carvalho GR, Cannon CH, et al Borneo and Indochina are Major Evolutionary Hotspots for Southeast Asian Biodiversity. Syst Biol. 2014;63(6):879-901.

40. Hall R. Southeast Asia's changing palaeogeography. Blumea. 2009:54(1-3):148-61

41. Hall R. Australia-SE Asia collision: plate tectonics and crustal flow. In: Hall R, Cottam MA, Wilson MEJ, editors. The SE Asian gateway: history and tectonics of Australia-Asia collision. London: Geological Society of London Special Publication; 2011. p. 75-109.

42. Hall R. Late Jurassic-Cenozoic reconstructions of the Indonesian region and the Indian Ocean. Tectonophysics. 2012;570:1-41.

43. Moss SJ, Wilson MEJ. Biogeographic implications from the Tertiary palaeogeographic evolution of Sulawesi and Borneo. In: Hall R, Holloway JD, editors. Biogeography and geological evolution of SE Asia. Leiden: Backhuys Publishers; 1998. p. 133. 
44. Vane-Wright RI. Transcending the Wallace Line: do the western edges of the Australian region and the Australian plate coincide? Aust Syst Bot. 1991;4(1):183-98.

45. Müller CJ. A new species of Nirvanopsis Vane-Wright (Lepidoptera: Nymphalidae) from the Sula Islands, Indonesia. Aust Entomol. 2004;31(Part 2):75-8.

46. Müller CJ, Beheregaray LB. Palaeo island-affinities revisited - Biogeography and systematics of the Indo-Pacific genus Cethosia Fabricius (Lepidoptera: Nymphalidae). Mol Phylogenet Evol. 2010;57(1):314-26.

47. Müller CJ, Wahlberg N, Beheregaray LB. 'After Africa': the evolutionary history and systematics of the genus Charaxes Ochsenheimer (Lepidoptera: Nymphalidae) in the Indo-Pacific region. Biol J Linn Soc. 2010;100(2):457-81.

48. Walton C, Butlin RK, Monk KA. A phylogeny for grasshoppers of the genus Chitaura (Orthoptera : Acrididae) from Sulawesi, Indonesia, based on mitochondrial DNA sequence data. Biol J Linn Soc. 1997;62(3):365-82.

49. Maekawa K, Kon M, Araya K, Matsumoto T. Phylogeny and biogeography of wood-feeding cockroaches, genus Salganea Stål (Blaberidae : Panesthiinae), in Southeast Asia based on mitochondrial DNA sequences. J Mol Evol. 2001;53(6):651-9.

50. Clouse RM, Giribet G. When Thailand was an island - the phylogeny and biogeography of mite harvestmen (Opiliones, Cyphophthalmi, Stylocellidae) in Southeast Asia. J Biogeogr. 2010;37(6):1114-30.

51. Allen MB, Armstrong HA. Arabia-Eurasia collision and the forcing of mid-Cenozoic global cooling. Palaeogeogr Palaeoclimatol Palaeoecol. 2008;265(1-2):52-8.

52. Kappelman J, Rasmussen DT, Sanders WJ, Feseha M, Bown T, Copeland P, et al. Oligocene mammals from Ethiopia and faunal exchange between Afro-Arabia and Eurasia. Nature. 2003;426(6966):549-52.

53. Rogl F. Mediterranean and Paratethys. Facts and hypotheses of an Oligocene to Miocene paleogeography (short overview). Geol Carpath. 1999;50(4):339-49.

54. Kodandaramaiah U, Wahlberg N. Out-of-Africa origin and dispersalmediated diversification of the butterfly genus Junonia (Nymphalidae : Nymphalinae). J Evol Biol. 2007;20(6):2181-91.

55. Aduse-Poku K, Vingerhoedt E, Wahlberg N. Out-of-Africa again: a phylogenetic hypothesis of the genus Charaxes (Lepidoptera: Nymphalidae) based on five gene regions. Mol Phylogenet Evol. 2009;53(2):463-78.

56. Sen S. Dispersal of African mammals in Eurasia during the Cenozoic: Ways and whys. Geobios. 2013;46(1-2):159-72.

57. Vidal N, Marin J, Sassi J, Battistuzzi FU, Donnellan S, Fitch AJ, et al. Molecular evidence for an Asian origin of monitor lizards followed by Tertiary dispersals to Africa and Australasia. Biol Lett. 2012:8(5):853-5.

58. Amer SAM, Kumazawa Y. Mitochondrial DNA sequences of the Afro-Arabian spiny-tailed lizards (genus Uromastyx; family Agamidae): phylogenetic analyses and evolution of gene arrangements. Biol J Linn Soc. 2005:85(2):247-60.

59. Yoder JB, Clancey E, Des Roches S, Eastman JM, Gentry L, Godsoe W, et al Ecological opportunity and the origin of adaptive radiations. J Evol Biol. 2010;23(8):1581-96.

60. Nosil P. Ecological Speciation. Oxford: Oxford University Press; 2012.

61. Wahlberg N, Leneveu J, Kodandaramaiah U, Peña C, Nylin S, Freitas AVL, et al. Nymphalid butterflies diversify following near demise at the Cretaceous/Tertiary boundary. Proc R Soc B Biol Sci. 2009;276(1677):4295-302.

62. Wahlberg N, Wheat CW. Genomic outposts serve the phylogenomic pioneers: designing novel nuclear markers for genomic DNA extractions of Lepidoptera. Syst Biol. 2008;57(2):231-42.

63. Lanfear R, Calcott B, Ho SYW, Guindon S. PartitionFinder: combined selection of partitioning schemes and substitution models for phylogenetic analyses. Mol Biol Evol. 2012;29(6):1695-701.

64. Miller MA, Pfeiffer W, Schwartz T. Creating the CIPRES Science Gateway for inference of large phylogenetic trees. In: Proceedings of the Gateway Computing Environments Workshop (GCE), 14 Nov. 2010, New Orleans, LA pp 1 - 8.http://www.plosone.org/annotation/listThread.action?root=9561

65. Ronquist F, Huelsenbeck JP. MrBayes 3: Bayesian phylogenetic inference under mixed models. Bioinformatics. 2003;19(12):1572-4.

66. Rambaut A, Suchard MA, Xie D, Drummond AJ: Tracer v1.6. In: http:// tree.bio.ed.ac.uk/software/tracer/. 2014.

67. Bouckaert R, Heled J, Kuehnert D, Vaughan T, Wu C-H, Xie D, et al. BEAST 2: a software platform for Bayesian evolutionary analysis. Plos Comput Biol. 2014;10(4):e1003537.
68. Condamine FL, Nagalingum NS, Marshall CR, Morlon H. Origin and diversification of living cycads: a cautionary tale on the impact of the branching process prior in Bayesian molecular dating. BMC Evol Biol. 2015;15:65.

69. Ree RH, Moore BR, Webb CO, Donoghue MJ. A likelihood framework for inferring the evolution of geographic range on phylogenetic trees. Evolution. 2005;59(11):2299-311.

70. Ree RH, Smith SA. Maximum likelihood inference of geographic range evolution by dispersal, local extinction, and cladogenesis. Syst Biol. 2008;57(1):4-14.

71. Yu Y, Harris AJ, He X. S-DIVA (Statistical Dispersal-Vicariance Analysis): A tool for inferring biogeographic histories. Mol Phylogenet Evol. 2010;56(2):848-50

72. Yu Y, Hall TA, Blair C, He XJ. RASP (Reconstruct Ancestral State in Phylogenies): a tool for historical biogeography. Molecular Phylogenetics and Evolution 2015;f 87 (doi:10.1016/j.ympev.2015.03.008):46-49.

73. Proches S, Ramdhani S. The World's Zoogeographical Regions Confirmed by Cross-Taxon Analyses. Bioscience. 2012;62(3):260-70.

\section{Submit your next manuscript to BioMed Central and take full advantage of:}

- Convenient online submission

- Thorough peer review

- No space constraints or color figure charges

- Immediate publication on acceptance

- Inclusion in PubMed, CAS, Scopus and Google Scholar

- Research which is freely available for redistribution

Submit your manuscript at www.biomedcentral.com/submit
C) Biomed Central 